Notes and miscellanea

\section{The effect of twelve-hour shift working on absence attributed to sickness}

\author{
A. WARD GARDNER AND B. D. DAGNALL \\ From the Esso Medical Centre, Esso Petroleum \\ Co. Ltd., Fawley, Southampton SO4 1TX
}

In a review of the medical and social aspects of shift work Taylor (1970) points out that many of the most important questions relating to shift work remain to be answered. One of these questions, on which evidence to date has been almost nonexistent, is the effect of a twelve-hour shift system on absence attributed to sickness. An opportunity to examine this occurred in 1973 when a change was made from an eight-hour to a twelve-hour shift work system by men employed as process workers in an oil refining and petrochemicals plant.

Under the eight-hour system, in eight weeks a shift worker had six periods of seven consecutive eight-hour shifts, four periods of two consecutive days off, and two periods of three consecutive days off-that is, 42 days at work, 14 off, with an average working week of 42 hours. Under the twelve-hour system, in eight weeks a shift worker has seven periods of four consecutive twelve-hour shifts, and seven periods of four consecutive days off-that is, 28 days at work, 28 off, with the same average working week of 42 hours.

Absence attributed to sickness is deemed to start on the first working day that a person is not at work and to end on the calendar day preceding return to work. A certificate to cover sickness absence is required after three days. Sick pay is paid for absence of both short and long duration. It includes the shift differential, which did not alter with the change in system.

\section{Material and methods}

A sample of 356 men who had experienced each shift system for at least a year was available The number of spells of absence attributed to sickness and the number of days lost were measured for equal periods before and after the change of shift

Received for publication 13 August 1976 Accepted for publication 10 November 1976
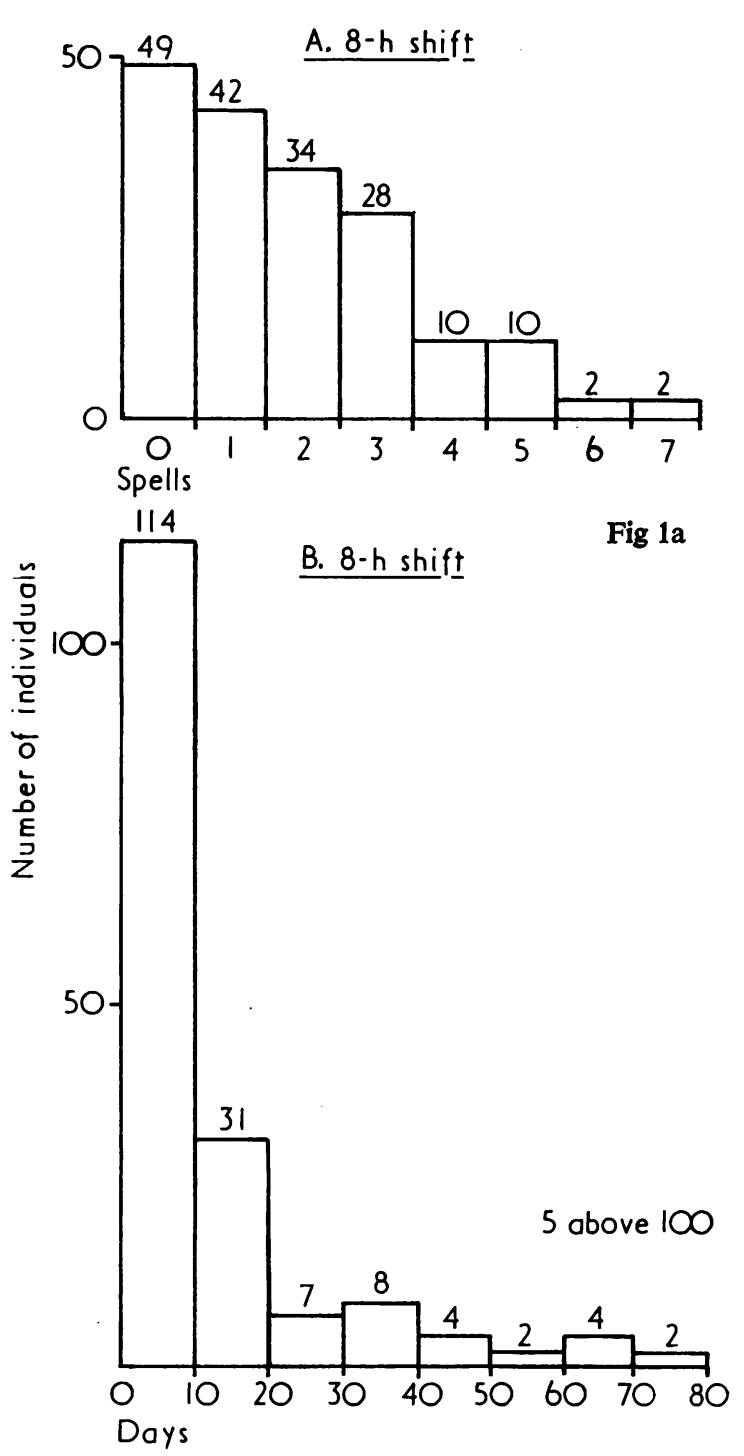

Fig 1b

Figs $1 \mathrm{a}$ and $\mathrm{b}$ Incidence of absence on $8 h$ shift before changing to $12 \mathrm{~h}$ shift.

system. For most shift workers the total time involved was 1,186 days, 593 days before and 593 days after the change. The actual time for each individual varied from 427 to 593 days because there was a certain amount of staggering in the change to the new shift work system. 


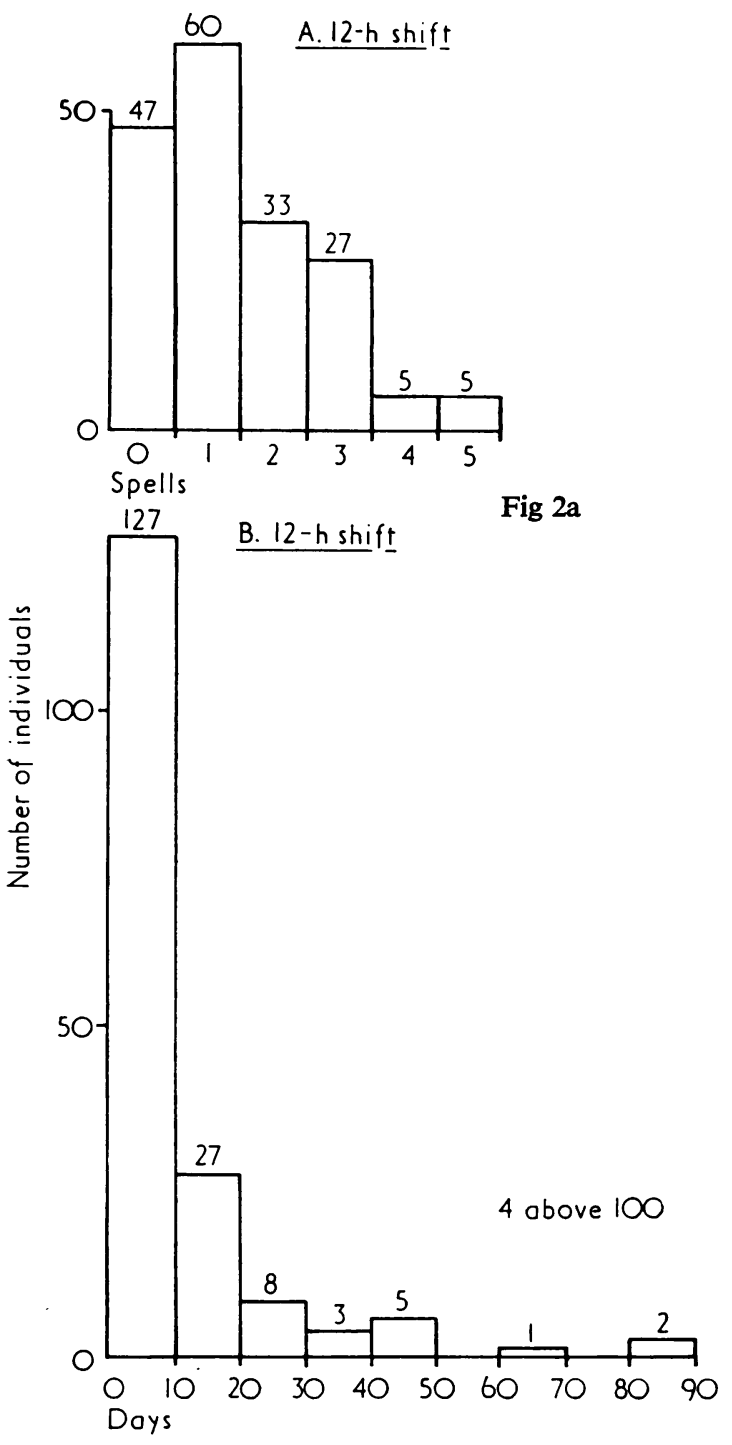

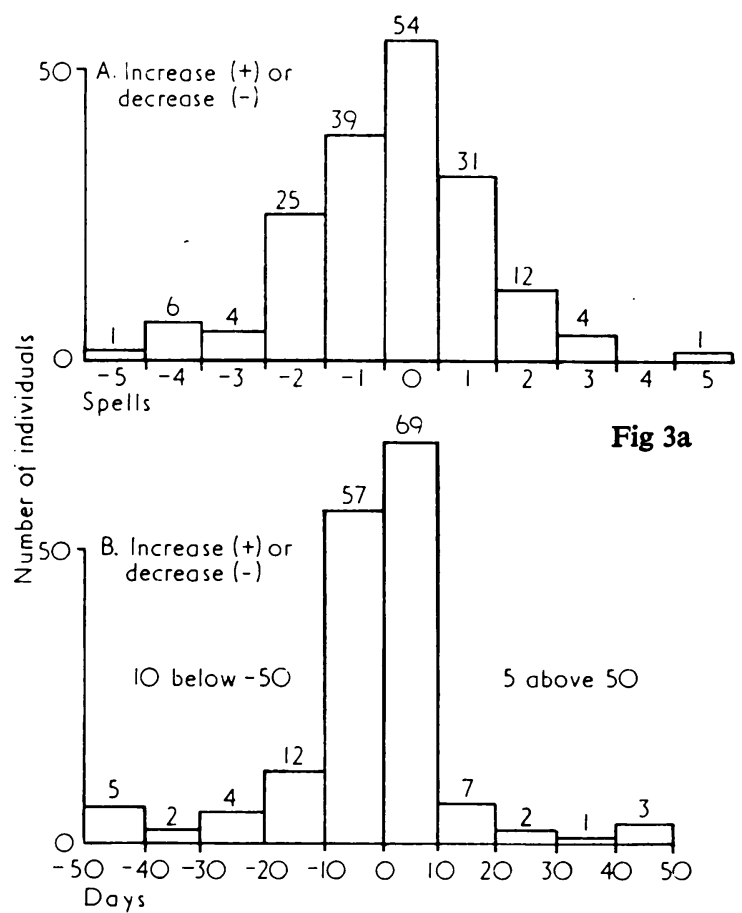

Fig 3b

Figs $3 \mathrm{a}$ and $\mathrm{b}$ Increase or decrease in absence after changing to $12 \mathrm{~h}$ shift system.

Figs $2 \mathrm{a}$ and $\mathrm{b}$ Incidence of absence on $12 \mathrm{~h}$ shift after changing from $8 h$ shift.

Fig $2 b$

\section{Results}

Incidence of absence before and after the change is shown in Figs. $1 a$ and $b$ and $2 a$ and $b$. The increase or decrease is shown in Figs. $3 a$ and $b$.

Absences attributed to sickness under the two systems for the whole sample of 356 men are shown in the Table. A $t$-test was applied to the increase or decrease in absence to establish whether liability to absence differs under the two systems. 
Table Effect on sickness absence of changing from an 8-hour to a 12-hour shift system

\begin{tabular}{|c|c|c|c|c|c|c|}
\hline & \multicolumn{3}{|c|}{ Spells of absence } & \multicolumn{3}{|c|}{ Days of absence } \\
\hline & $\begin{array}{l}8 \mathrm{~h} \\
\text { system }\end{array}$ & $\begin{array}{l}12 \mathrm{~h} \\
\text { system }\end{array}$ & $\begin{array}{l}\text { Increase or } \\
\text { (decrease) }\end{array}$ & $\begin{array}{l}8 \mathrm{~h} \\
\text { system }\end{array}$ & $\begin{array}{l}12 \mathrm{~h} \\
\text { system }\end{array}$ & $\begin{array}{l}\text { Increase or } \\
\text { (decrease) }\end{array}$ \\
\hline $\begin{array}{l}\text { Total } \\
\text { Average } \\
t \\
\text { Probability* }\end{array}$ & $\begin{array}{l}643 \\
1.81\end{array}$ & $\begin{array}{l}689 \\
1.94\end{array}$ & $\begin{array}{l}46 \\
0 \cdot 13 \\
1 \cdot 25 \\
0 \cdot 22\end{array}$ & $\begin{array}{c}6321 \\
17 \cdot 8\end{array}$ & $\begin{array}{c}6006 \\
16.9\end{array}$ & $\begin{array}{c}(315) \\
(0.9) \\
0.46 \\
0.63\end{array}$ \\
\hline
\end{tabular}

*Probability of $t$ as large as this occurring by chance in a sample of this size.

the return to work, unless the sickness is completely within an off-duty period, in which case it is not recorded. Thus the 'before' and 'after' results are not strictly comparable because the duration and frequency of off-duty periods were different in the two cases. It was not possible to correct for this effect because of lack of knowledge of sickness when off duty. In addition, the men were about a year and a half older in the twelve-hour shift study period than in the earlier one, but the effect of this is judged to be small. Despite these reservations it is considered that any large effect would have been revealed by this comparison. The effect, if any, must therefore be small. We therefore conclude that from this study there is no evidence that changing from an eight-hour to a twelve-hour shift system had any significant effect on absence attributed to sickness.

\section{Reference}

Taylor, P. J. (1970). Shift work-some medical and social factors. Transactions of Society of Occupational Medicine, 20. 127-132. 